\title{
ANALYZING THE EFFECT OF CLIMATE CHANGE (RAINFALL AND TEMPERATURE) ON VEGETATION COVER OF NEPAL USING TIME SERIES MODIS IMAGES
}

\author{
Neha Joshi ${ }^{1}$, Pradeep Gyawali ${ }^{1}$, Sudha Sapkota ${ }^{1}$, Dinesh Neupane ${ }^{1}$, Sanjeevan Shrestha ${ }^{2,}$, Nawaraj Shrestha ${ }^{1}$, Florencia \\ Matina Tuladhar ${ }^{1}$ \\ ${ }^{1}$ Department of Civil and Geomatics Engineering, Kathmandu University, Dhulikhel, Nepal - nehajoshi3113@ gmail.com, \\ pradeep2gyawali@gmail.com, sudhasapkota5@gmail.com, dinesh.neupane5@gmail.com, nawa.shrestha@ku.edu.np, \\ ftuladhar@gmail.com \\ 2 Department of Photogrammetry and Remote Sensing, Land Management Training Centre, Government of Nepal - \\ shr.sanjeevan@gmail.com
}

KEY WORDS: MODIS image, NDVI, CHIRPS, Vegetation change pattern, Climate change, Time series data

\begin{abstract}
:
Climate change and so its effect on terrestrial ecosystem has been a focus point for a while now. Among them, rainfall and temperature changes happen to exert a strong influence on the condition of vegetation cover. So, it is imperative to analyze the variation and inter-relationship between vegetation cover and climate pattern, especially country like Nepal having a dynamic ecosystem. This paper aims to analyze the spatial-temporal distribution of vegetation cover, temperature, and rainfall, and to examine the relationship of the latter two with vegetation for entire Nepal. Primary data used were vegetation and temperature data from Moderate Resolution Imaging Spectroradiometer (MODIS) and rainfall data from Climate Hazards Group Infrared Precipitation with Stations (CHIRPS) data product. The relationship analysis was carried out in three phases; first, the trend of vegetation with respect to rainfall and land surface temperature (LST) was inspected over entire study area by creating a time series of Normalized Difference Vegetation Index (NDVI) monthly means for six months, averaged over the whole study period. However, vegetation change pattern across various ecological regions of Nepal also needed to be considered, for the three different regions are profoundly different from each other in a number of factors like altitude and soil type. Finally, the variation of vegetation with climatic parameters, i.e. rainfall and temperature, along the eleven-year study period was also portrayed, to depict how the vegetation cover has been fluctuating over the years. During the study period, the correlation coefficient between vegetation index and rainfall was the highest in October in Terai while that with temperature was in July in Hilly region. Overall, vegetation was influenced greater by the temperature than rainfall in all three ecological regions with the highest correlation coefficient of vegetation with temperature and rainfall, being -0.937 and 0.556 respectively.
\end{abstract}

\section{INTRODUCTION}

Vegetation dynamics and responses to the climate change have been recognized as one of the key issues in global change of terrestrial ecosystem (Fu \& $\mathrm{Li}, 2010)$. Among them, precipitation and temperature strongly influence the vegetative conditions (Li, Jianrong, \& Yang, 2014). In particular, monsoon precipitation and temperature are well known to affect vegetation distribution. Because vegetation requires humidity, rain, and favorable temperatures, regional weather can be characterized by these parameters. Changes in vegetation and land use / land cover are closely correlated with changes in seasonal precipitation and land temperature, which in turn have effect on regional climate.

Rainfall and temperature pattern are varying and, atmospheric $\mathrm{CO} 2$ concentrations is increasing due to anthropogenic activities contributing to climate change. Therefore, study on effect of climate changes in vegetation is essential to identify the ecosystem functions for providing a scientific basis for corresponding policies.

Currently available field data are not sufficient enough for the regional scale implementation as they are collected at small spatial scale and vary in their reliability. Satellite imagery has become source for analyzing that context due to its high spatial and temporal resolution. The information derived from the satellite-based data (such as vegetation distribution, temperature and rainfall pattern in our case) is of importance for analyzing vegetation dynamics and its response to climate change. The monitoring of vegetation by remote sensing is an accepted technique of resource assessment. Due to high spatial and temporal resolutions and accuracy, remotely sensed data can provide technical support for monitoring vegetation dynamics at large scales. The Normalized Difference Vegetation Index (NDVI) was proposed by Rouse et al. based on red and nearinfrared reflectance, has been frequently used for studying vegetation dynamics because it is highly correlated with the photosynthetic capacity, the leaf area index, biomass, and net primary productivity (Ning et al., 2015). For large areas comprising vegetation, NDVI method is better suitable where analysis is carried out using either past or present images with no ground truth data (AS et al., 2012). Moreover, the availability of long-term, repetitive satellite-derived datasets to derive and measure temperature and rainfall pattern are abundant which open the door for analyzing temperature and rainfall pattern in larger scale.

\footnotetext{
* Corresponding author
} 
Nepal is a country with a dynamic ecosystem that responds to fluctuations in climate and anthropogenic land use patterns. So, it is imperative to analyze the variation and inter-relationship between vegetation cover and climate pattern, possibly to forecast the biomass production (Baniya et al, 2018). The integration of satellite remote sensing in combination with field ground measurements is particularly appropriate for monitoring this context, especially a country like Nepal with variant ecological belts. Most previous regional-scale studies were based on time series vegetation cover derived from the satellite images and the field-based measurement of temperature and rainfall measurements from weather stations (Liang S., 2004). This research attempts to study the vegetation cover dynamics as an effect of rainfall and temperature over six months' period from 2000 to 2010 by using geospatial techniques. For this, spatialtemporal variation of vegetation using NDVI and temperature pattern are derived from the MODIS products, gridded satellite rainfall (CHIRPS) time series, measured rainfall and temperature over the study area at different weather ground stations were used.

\section{STUDY AREA}

The study area covers whole Nepal $\left(28.3949^{\circ} \mathrm{N}, 84.1240^{\circ} \mathrm{E}\right)$ with an area of 147,181 square kilometers. Nepal is landlocked by India on three sides and China's Tibet Autonomous Region to the north. Nepal measures about 800 kilometers along the Himalayan axis by 150 to 250 kilometers across. It rises from low of 59-meter elevation in tropical Terai to 8848 meters in the hill. Along south-to-north it can be divided into three belts: Lower Plains, Mountain and Hill. The Lower Plains, also called Terai, begins at the Indian border and includes some hill ranges. The southernmost part of Terai is flat and intensively farmed North-Indian River Plain and is called Outer Terai. The hilly area contains the region which generally doesn't contain snow. This area lies at an altitude of 1500-2700 meters. The Mountain Region or Parbat rises above 3000 meters that constitutes the subalpine and alpine zone which are mainly used for seasonal pasturage. The major altitude belts of Nepal are Tropical Zone (below 1000 meters), Subtropical Climate Zone $(1,000$ to 2,000 meters), Temperature Climate Zone (2,000 to 3,000 meters), Subalpine Zone (3,000 to 4,000 meters) and Alpine zone (4,000 to 5,000 meters).

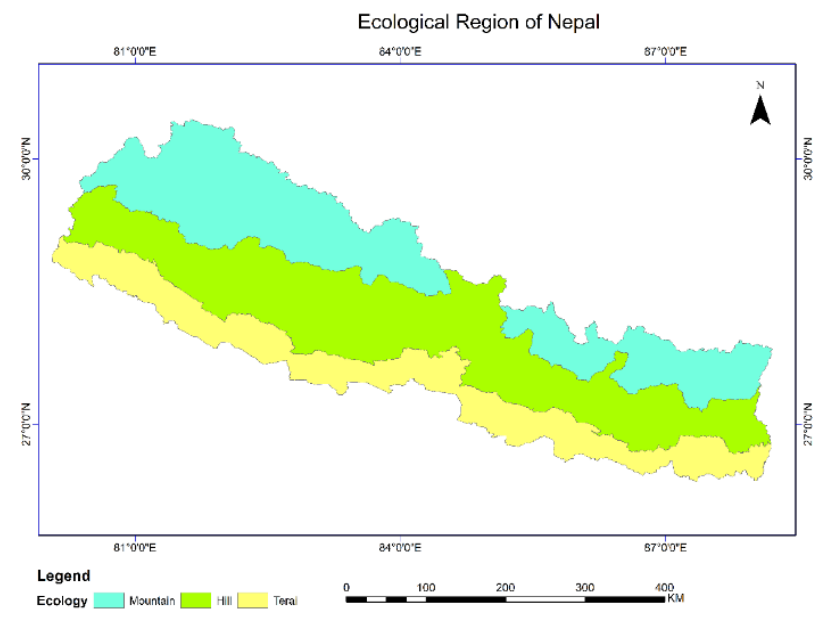

Figure 1. Study area

\section{METHODOLOGY}

\subsection{Data Acquisition}

The primary datasets used were NDVI and LST from MODIS satellite product and monthly CHIRPS gridded precipitation datasets from the $\mathrm{CHG}$ archives. Data with one-kilometer spatial resolution is extracted on monthly basis to assess vegetation status while an average, 8-day, per-pixel LST in a $1200 \times 1200$ kilometer grid was downloaded where each pixel value in the MOD11A2 is a simple average of all the corresponding MOD11A1 LST pixels collected within that 8-day period. On the other hand, satellite imagery of $0.05^{\circ}$ resolution with in - situ station data was used to create gridded rainfall time series for rainfall time series for rainfall trend analysis.

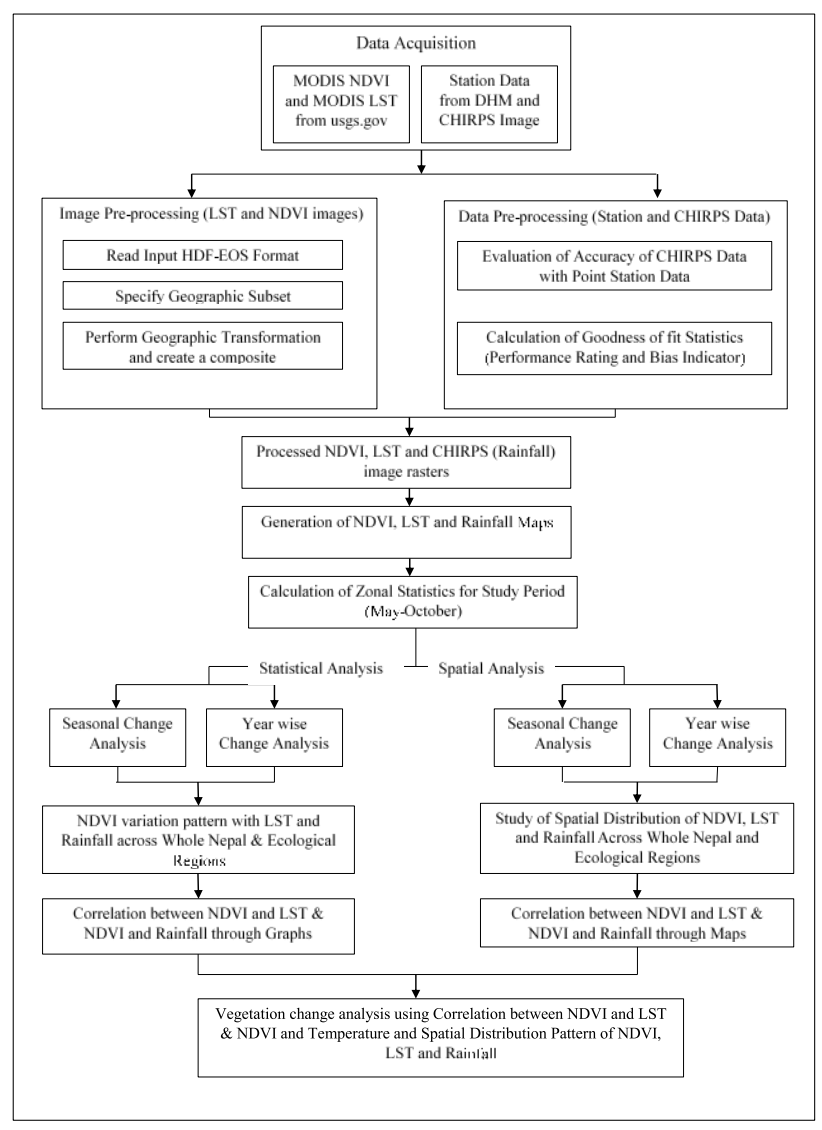

Figure 2. Workflow of the project

Validation of Remote Sensing Products (RSPs) is fundamental work prior to proper use of RSPs and validation at pixel scale was carried out for this project. The validation process can be summarized with major three steps:

a) sampling design for ground observation,

b) data collection,

c) and estimation of the mean value at pixel scale.

Rain Gauge Station Precipitation data and Google Earth Data were used for validation. Data from Google Earth were used to verify extent of vegetation coverage. Precipitation data from 2000-2010 with monthly resolution (obtained from Survey Department of Nepal), were used for checking the quality of monthly CHIRPS precipitation dataset. The rain gauge network 
was chosen such that it covered Mountain, Terai, and Hilly regions uniformly.

\subsection{Image Pre-processing}

The original MODIS products downloaded from USGS website, i.e. both LST and NDVI come in HDF-EOS format with sinusoidal coordinate system. Then after they were preprocessed in the software called MODIS Reprojection Tool. The functionalities of the tools that the software provides can be achieved both from the command-line and from the GUI. Considering the huge sets of data to be processed, batch processing via command- line was opted to avoid the repetition of the task.

MRT was used for two major reasons: create a mosaic, and project HDF format to tiff and reprojection from sinusoidal to WGS84.

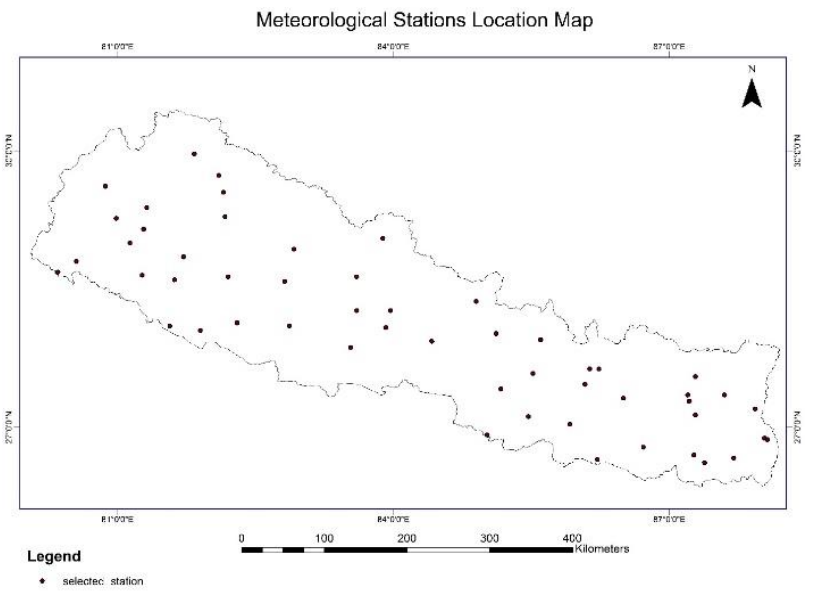

Figure 3. Map showing distribution of selected meteorological stations in Nepal

\subsection{Validation of Downloaded Data}

Because of low spatial resolution of CHIRPS data, it was validated prior its use to ensure sufficient credibility to be used in the project.

Pixel - to - pixel comparison was performed to compare satelliteand ground - based rainfall products. Based on sample stations selected across Nepal, a total of 53 region of interest (ROI) were generated in ENVI. The monthly average was subsequently generated for the whole study period, i.e. 2000 to 2010 , for the pixels associated with the region of interest. On the other hand, the daily precipitation data from the Hydrology and Meteorology Department (DHM) were processed and the pivot table was used to generate a monthly average for each station in MS Excel.

After all the necessary data were generated to evaluate the accuracy of the satellite-based products when compared against the ground-based rainfall depths, a goodness of fit statistics was used, namely the percentage bias - PBIAS ( Shrestha et al., 2017).

$$
\text { PBIAS }=\frac{\sum(\text { Rgauge }- \text { Rsatellite })}{\sum(\text { Rgauge })} * 100,
$$

where Rsatellite $=$ rainfall estimates from the $\mathrm{CHG}$ product Rgauge $=$ rainfall recorded in a particular rain gauge.

Afterwards, monthly precipitation and difference of monthly precipitation of CHIRPS and rain gauge stations were generated, averaged for all sample stations for a given month to analyze the bias of the CHIRPS data.

\subsection{Generate Vegetation Cover Map, Temperature Map and Rainfall Map}

To analyze the seasonal evolution of vegetation, an average of the NDVI images over the study period from 2000 to 2010 is taken for each month.

It was carried out for all the months consecutively from May to October. The same was done for LST as well as CHIRPS, and hence vegetation, temperature and rainfall map were generated. As the analysis required the independent average value for each ecological region, 'zonal statistics' was used in order to derive the average value of each parameter for all the ecological regions.

\subsection{Establishment of Relationship of Vegetation with Temperature and Rainfall}

The analysis was carried out through two approaches, statistical and spatial. Under each type of analysis, further two approaches were opted to show the relationship, seasonal change and yearwise change. The variation in vegetation alongside the change in rainfall and temperature was analyzed month-wise in order to identify the impacts that the temperature and rainfall has on vegetation in each month through pre-monsoon to postmonsoon. Meanwhile, our analysis was guided by average data of eleven- years period. So to ensure if there are any abrupt changes in any given year that would deviate the final average, the analysis was made to inspect year-to-year impacts of these climatic parameters.

For statistical analysis, the data so generated were then represented in the graphs that supported the analysis while on the other hand, study of spatial distribution of the all three maps of NDVI, LST and rainfall was made for spatial analysis. Besides, the correlation maps indicating the relationship of NDVI with rainfall and temperature individually, were also generated using $\mathrm{R}$ script to help with the analysis. Afterwards, the analysis from both the approaches were brought together so as to condense the overall analysis to the final result.

\section{RESULTS AND DISCUSSION}

4.1 Relationship between NDVI and Climate Variables (Rainfall and Temperature) for Ecological Regions of Nepal

In first case, the analysis was guided by average data of elevenyears period, i.e. 2000 to 2010 to describe the variation of vegetation. The graphs in figure 4 depicts the relationship between NDVI and rainfall in three ecological regions of Nepal. 


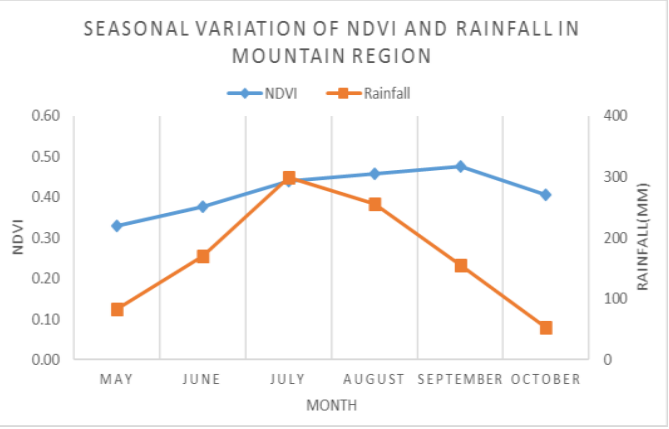

(a)

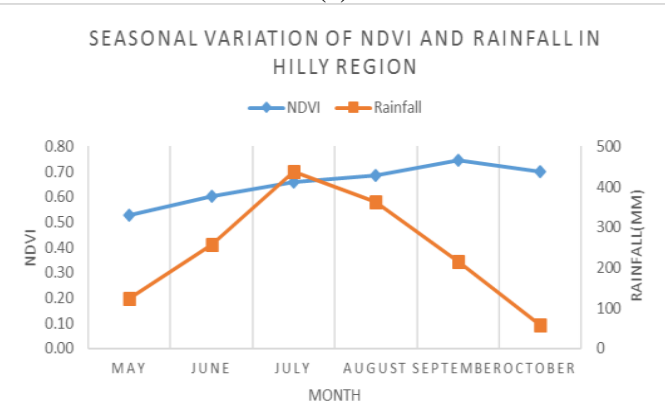

(b)

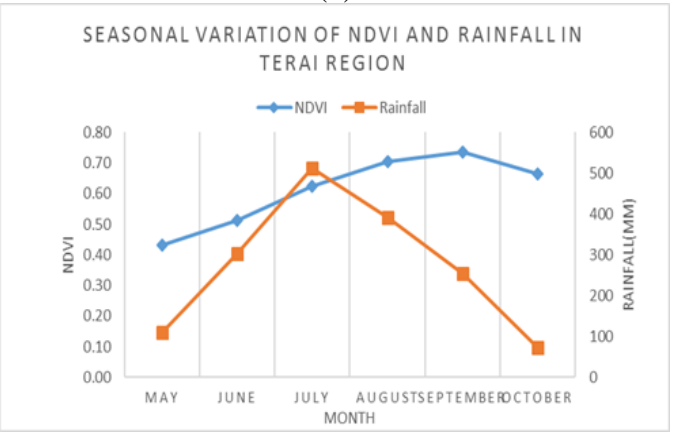

(c)

Figure 4 (a)-(c). Graph showing seasonal variation of NDVI with rainfall across (a). mountain, (b). hilly and (c). terai region

Although all three ecological regions depict similar trend, but the maximum NDVI and precipitation value attained in each region was different for a given particular month. In the beginning of study period, the value for both NDVI and rainfall was least for May as a result of comparatively limited amount of vegetation and so the precipitation. With the onset of monsoon, the precipitation increased vigorously, however, the growth in vegetation could not be instantly seen. The water requirement of plants would then be sufficiently fulfilled due to monsoon rainfall as it helps to retain adequate moisture availability in soil so that the plant roots can easily extract water from soil for their growth. Accordingly, by the end of monsoon, NDVI tended to increase but by then, the rate of precipitation decreased deliberately.

The semi-arid land with minimal humidity and the fact that, the area is mostly covered by ice and glaciers, may have led to limited vegetation in mountain region (Baniya et al., 2018), as a result, very low response between the two variables was displayed. The hills had high NDVI values due to the presence of a large number of community forestry and agricultural practices while in Terai cultivated lands were high (Baniya et al., 2018) which supported the high NDVI values that the region had. Meanwhile, in some cases NDVI showed increase in its value even in those areas that did not receive adequate amount of rainfall, which can be due to the artificial irrigation carried out by people on their own.

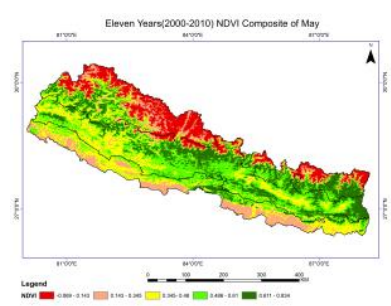

(a)

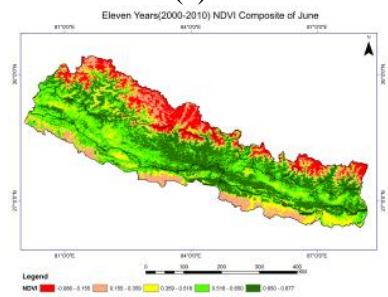

(b)

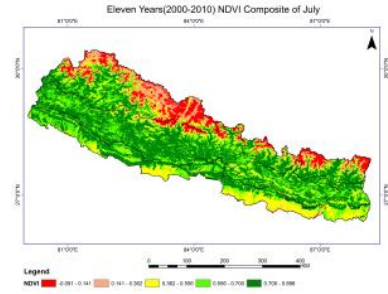

(c)

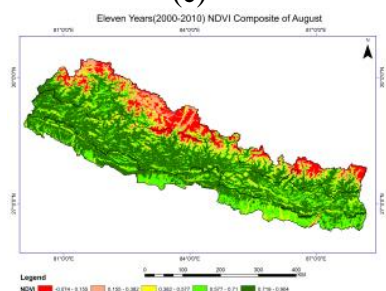

(d)

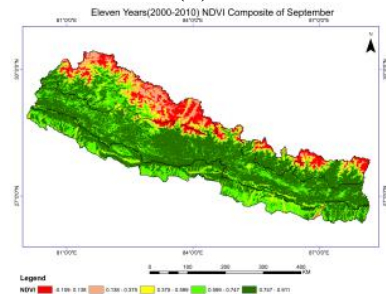

(e)

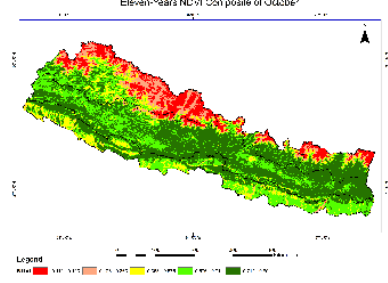

(f)

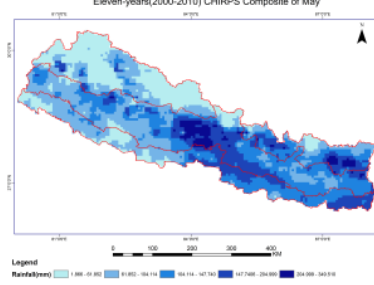

(i)

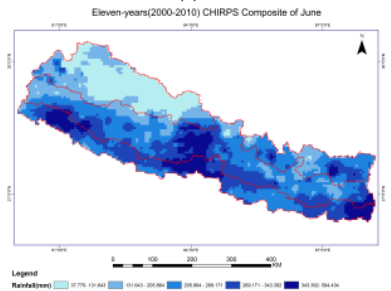

(ii)

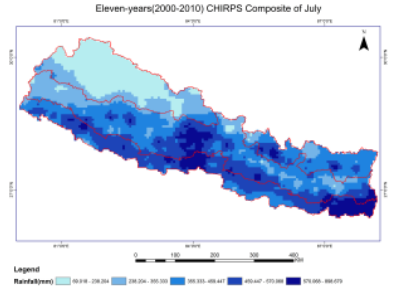

(iii)

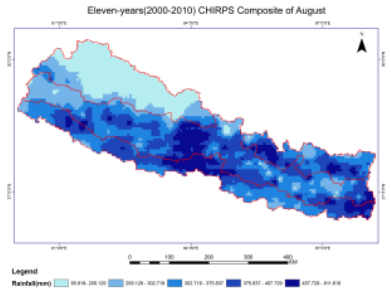

(iv)

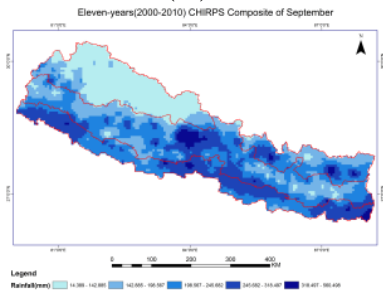

(v)

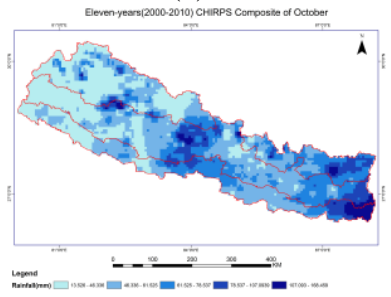

(vi)
Figure 5. Map showing NDVI eleven-years composite for (a). May, (b). June, (c). July, (d). August, (e). September and (f). October and map showing CHIRPS eleven-years composite for (i). May, (ii). June, (iii). July, (iv). August, (v). September and (vi). October. 
Relationship Between NDVI and Temperature

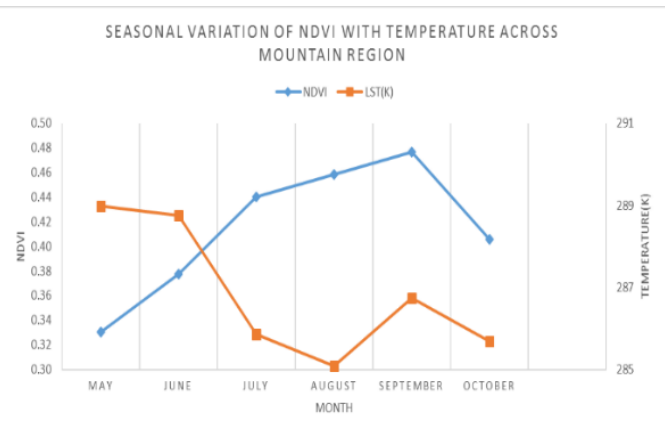

(a)

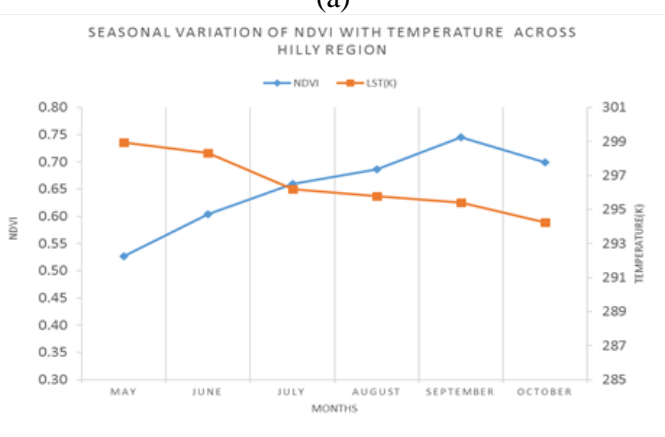

(b)

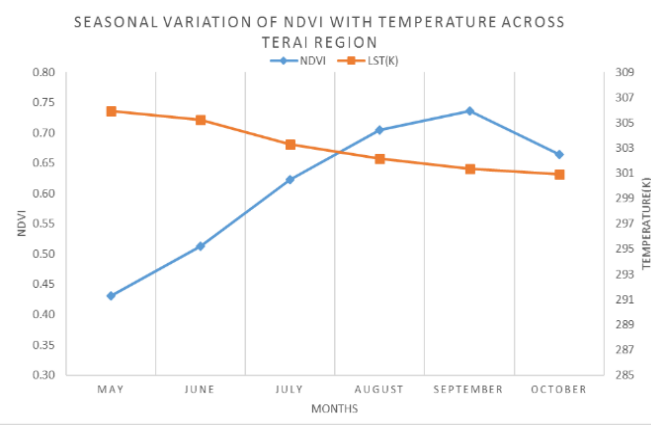

(c)

Figure 6 (a)-(c). Graph showing seasonal variation of NDVI with Temperature across (a).mountain, (b).hilly and (c). terai region

The LST value is greatly affected by altitude. The maps and graphs (figure 6 and 7) together depicted the fact that, unlike precipitation, the temperature showcased inverse relationship with vegetation. The temperature was the highest amongst all, in May while the vegetation was likely to be the least. As the month progressed, the temperature showed decreasing trend while the NDVI values showed the exact opposite. But this trend continued until the temperature was high. By the time it was October, both NDVI and temperature showed downward trend suggesting that, NDVI stayed inversely proportional to high temperature but once the temperature values started decreasing, NDVI almost became immune to its effect.

Apart from the negative pattern showcased by LST and NDVI in graphs (figure 6), an additional fact was shown by the maps (figure 7), i.e. the impact of temperature was seen to be least in the mountain region. This could be explained by the fact mentioned above that, as the temperature starts decreasing, its effect on vegetation too, subsides. Therefore, lesser the temperature, smaller its effect on vegetation. Also, the vegetation density in that region is way too low, which could also be one of the many reasons for it to not show the distinct impacts of temperature on its vegetation.

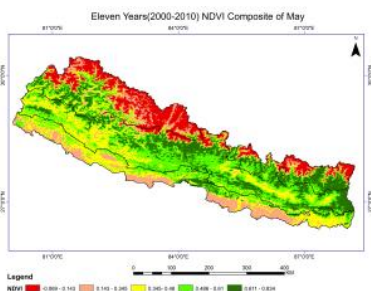

(a)

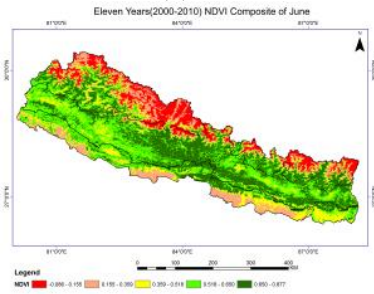

(b)

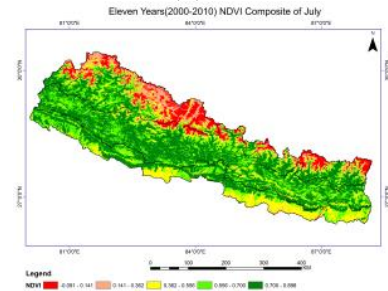

(c)

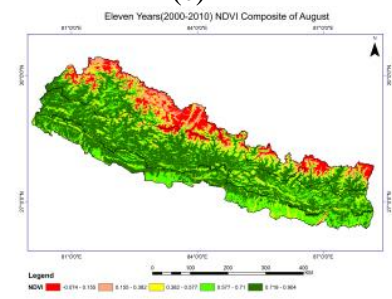

(d)

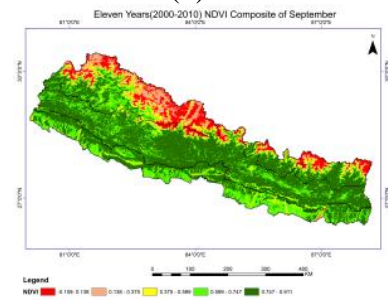

(e)

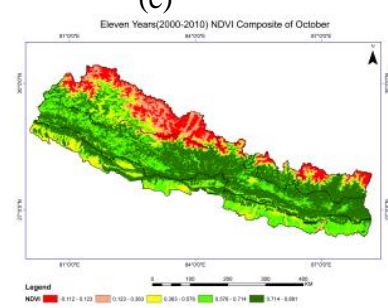

(f)

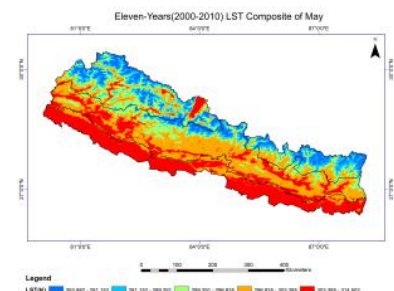

(i)

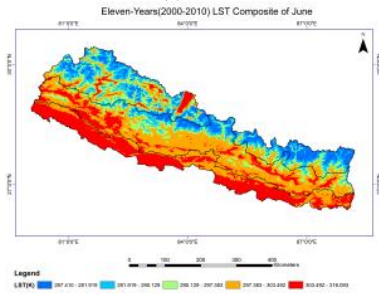

(ii)

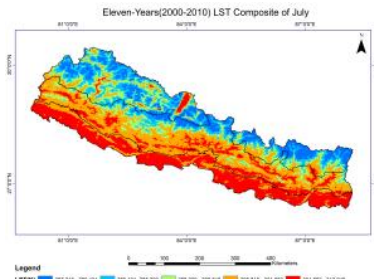

(iii)

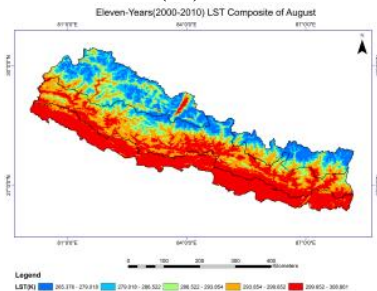

(iv)

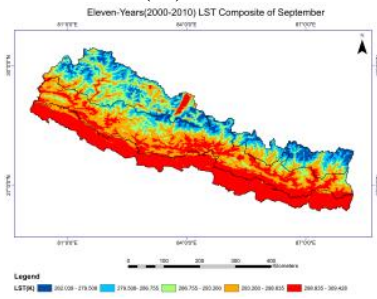

(v)

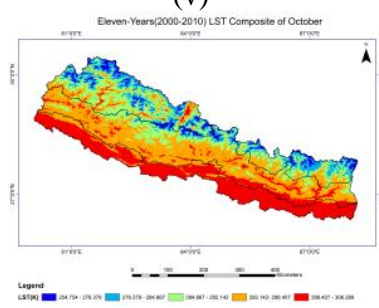

(vi)
Figure 7. Map showing NDVI eleven-years composite for (a).May, (b).June, (c).July, (d).August, (e).September and (f).October and map showing temperature eleven-years composite for (i).May, (ii).June, (iii).July, (iv).August, (v).September and (vi).October 


\subsection{Correlation Coefficient Values between Monthly NDVI and Monthly (a)Mean Rainfall and (b)Mean LST across three ecological regions}

The correlation table (table 1) indicating the relationship between the rainfall and NDVI well reflects the fact that NDVI and rainfall are positively correlated but the strength of correlation is really poor while the one with NDVI and temperature suggests (table 2), in each of the ecological region, the average value of LST and NDVI are negatively yet, highly correlated showing there is inverse relationship between them. Lower value of LST is characterized by the higher value of NDVI.

\begin{tabular}{|c|c|c|c|}
\hline Month & Mountain & Hill & Terai \\
\hline May & 0.341 & 0.209 & 0.572 \\
\hline June & -0.426 & 0.288 & 0.611 \\
\hline July & -0.021 & 0.143 & 0.455 \\
\hline August & -0.426 & -0.596 & -0.177 \\
\hline September & -0.189 & -0.014 & 0.292 \\
\hline October & -0.117 & 0.31 & -0.793 \\
\hline
\end{tabular}

Table 1. Correlation coefficient between NDVI and rainfall (r(NDVI, Rainfall)) across different ecological regions during the period of study

\begin{tabular}{|c|c|c|c|}
\hline Month & Mountain & Hill & Terai \\
\hline May & 0.64 & 0.018 & 0.0175 \\
\hline June & 0.357 & -0.334 & -0.728 \\
\hline July & 0.011 & 0.76 & -0.039 \\
\hline August & 0.441 & 0.48 & 0.281 \\
\hline September & 0.485 & 0.753 & 0.621 \\
\hline October & 0.54 & 0.163 & 0.038 \\
\hline
\end{tabular}

Table 2. Correlation coefficient between NDVI and temperature (r(NDVI, LST)) across different ecological regions during the period of study

As precipitation does not immediately put an impact on vegetation and requires a month or so to have its effect in action, the analysis of this delayed effect of seasonal rainfalls to NDVI showed vague correlation, as seen on the map (figure 7a). But on detailed inspection, the map tends to deliver poor relationship of NDVI to rainfall, closely limiting to 0 in most cases, throughout the study area.

On the other hand, the correlation map of NDVI relating to temperature (figure $7 \mathrm{~b}$ ) shows befitting relationship as obtained from the statistical prospect. The statistical part claimed NDVI to have strong negative relationship with temperature which is why the hills and the Terai depict high negative correlation values, for the vegetation density is greater on that region while the mountains claim positive relationship which do not entirely justify the statistics because it is the aggregate for six whole months, which can be the reason for slight deviation in the results.

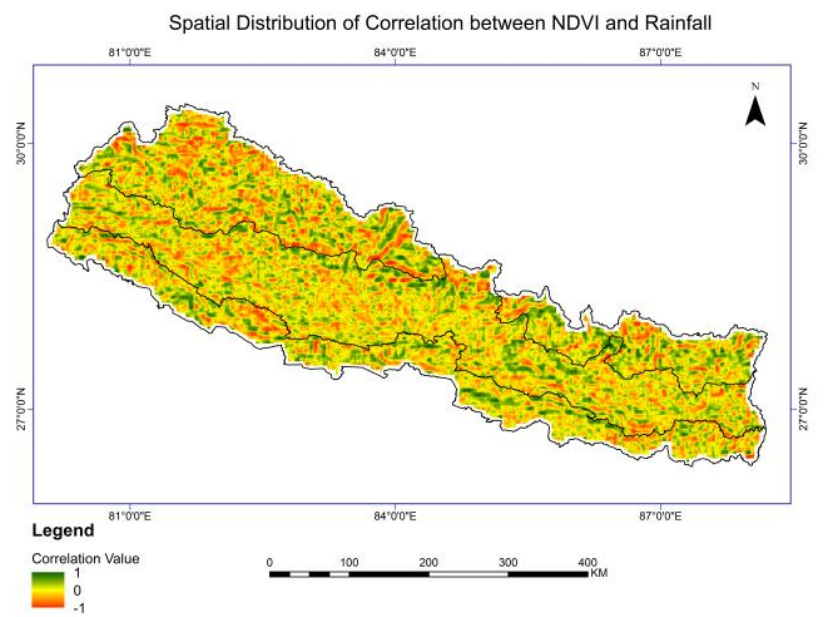

(a)

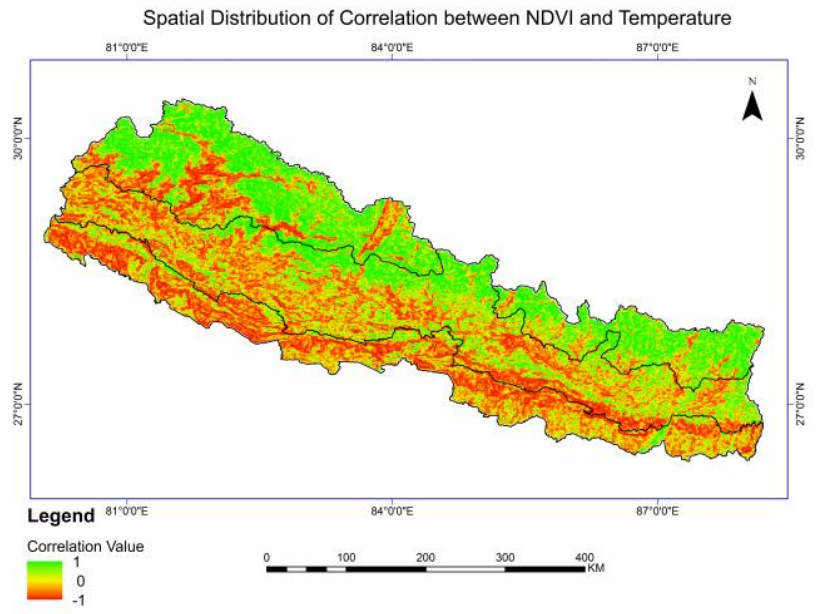

(b)

Figure 7. Spatial distribution of correlation between mean NDVI and climate factors (a. rainfall b. temperature) for six months' period

\subsection{Validation of CHIRPS Data}

While rainfall estimates based on satellite measurements are becoming a very attractive option, they are characterized by nonnegligible biases (Shrestha, et al., 2017). As such, the accuracy of satellite product of the Climate Hazard Group (CHG) was assessed using ground-based measurements through the following graphs and plots.

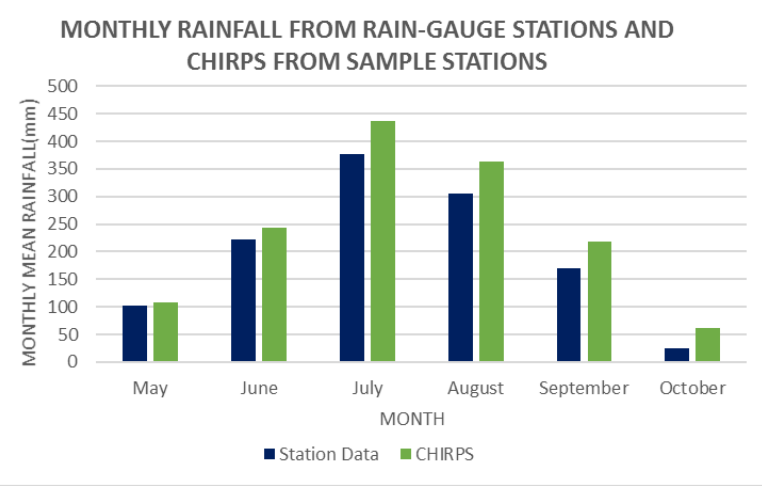

Figure 8. Monthly precipitation of CHIRPS and rain gauges, for all sample stations 


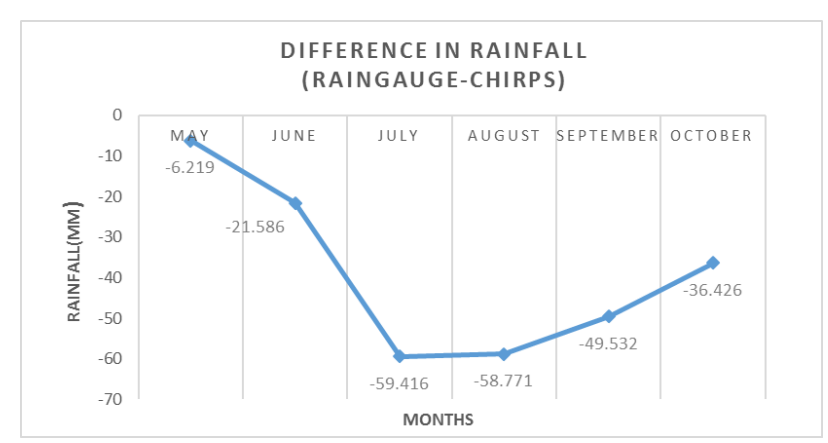

Figure 9. Difference in monthly precipitation, between CHIRPS and rain gauges, for all sample stations

From the graph in figure 8 and 9 , the difference in rain gauge station data and CHIRPS data seem fairly comparable, given that the PBIAS value is also in range for good performance rating where, PBIAS was found to be $-19.2763 \%$ which considerably falls under good performance rating based on the table 3 :

\begin{tabular}{|l|l|}
\hline Performance rating & PBIAS (\%) \\
\hline Very Good & $< \pm 15$ \\
\hline Good & $\pm 15- \pm 30$ \\
\hline Satisfactory & $\pm 30- \pm 55$ \\
\hline Unsatisfactory & \pm 55 \\
\hline
\end{tabular}

Table 3. Performance rating of CHIRPS data (Shrestha et al., 2017)

As the $\left(0.05^{\circ} \times 0.05^{\circ}\right)$ resolution CHIRPS data was validated against the point station data, the grid data could be considered satisfactory on this regard.

\section{CONCLUSION}

The project discussed the spatial-temporal patterns and relationships of NDVI with LST and gridded satellite rainfall throughout the study period. Both precipitation and temperature are dominant climate factors contributing to the vegetation growth in the study area. The correlation analysis with significant NDVI, LST and CHIRPS trends indicated that precipitation showed strong and positive impact on vegetation at most places while temperature had a significant negative impact. NDVI was more susceptible to the variations of rainfall and temperature in Hilly and Terai while the impact appeared to be least in Himalayan region, for it has low vegetation density as compared to prior two, as an effect of topography and altitude. Overall, the impact of temperature was seen to be greater than rainfall as a whole.

Meanwhile, there are other factors that need to be considered on the influence of terrestrial vegetation growth, such as relative humidity, nutrients, light intensity and mechanical factors including wind and occurrence of fire, and so on (Breckle, 2002). So, incorporating other climatic factors for better analysis on climate impact is highly recommended.

\section{REFERENCES}

Ali, M., 2012. Effects of Climate Change on Vegetation. Springer Netherlands, 29-49.

AS, C., GK, V., MVSS, G., \& P, S., 2012. Assessment of land use land cover changes in middle Godavari (G-5) sub-basin of river Godavari using RS and GIS. International Conference on Water Resources.

Baniya, B., Tang, Q., Huang, Z., Siao, S., \& Techato, K.-a., 2018. Spatial and Temporal Variation of NDVI in Response to Climate Change and the Implication for Carbon Dynamics in Nepal. Forests, 18.

Barrett, E. C., 1989. Satellite Remote Sensing of Rainfall. Applications of Remote Sensing to Agrometeorology, 305-326.

Damizadeh, M., Saghafian, B., \& Gieske, A., 2001. Studying Vegetation Responses And Rainfall Realatioonship based on NOAA/AVHR images. Asian Conference on Remote Sensing.

Fu, B., \& Li, S., 2010. Chinese ecosystem research network: progress and perspectives. Ecological Complexity, 225-233.

Funk, C. C., Peterson, P. J., Landsfeld, M. F., Pedreros, D. H., \& Verdin, J. P., 2014. A Quasi-Global Precipitation Time Series for Drought Monitoring. USGS, Data series 832.

Harrington, S., Teitelman, J., Rummel, E., Morse, B., Chen, P., Eisentraut, D., \& McDonough, D., 2017. Validating Google Earth Pro as a Scientific Utility. SAE international.

Kaufmann, K. r., Zhou, L., Myneni, B. R., Tucker, J. C., Slayback, D., Shabanov, V. N., \& Pinzon, J., 2003. The effect of vegetation on surface temperature: A statistical analysis of NDVI and climate data. The Research Letters.

Li, L., Jianrong, F., \& Yang, C., 2014. The relationship analysis of vegetation cover, rainfall and land urface temperature based on remote sensing in Tibet, China. IOP Conference Series: Earth and Environmental Science.

Liang, S., 2004. Quantitative Remote Sensing of Land Surfaces. Hoboken, New Jersey: John Wiley \& Sons

Ning, T., Liu, W., Lin, W., \& Song, X., 2015. NDVI Variation and Its Responses to Climate Change on the Northern Loess Plateau of China from 1998 to 2012. Advances in Meteorology.

Pandey, A., Kumar, D., Pandey, R., Mishra, S. k., \& Palmate, S., 2017. Climate change impact on forest cover and vegetation in Betwa Basin, India. Applied Water Science.

Shrestha, N. K., Qamer, F. M., Pedreros, D., Murthy, M., Wahid, S. M., \& Mandira, S., 2017. Evaluating the accuracy of Climate Hazard Group (CHG) satellite. Journal of Hydrology: Regional Studies.

Sttenekam, S. J., \& Bosch, O., 1995. The influence of rainfall on vegetation composition in different conditional states. Journal of Arid Environment, 185-190.

Wan , Z., \& Dozier, J., 1996. A Generalized Split- Window Algorithm for Retrieving Land-Surface Temperature from Space. IEEE Transactions on Geoscience and Remote Sensing.

Xie, Y., Sha, Z., \& Yu, M., 2008. Remote sensing imagery in vegetation mapping: a review. Journal of Plant Ecology.

Yan, D., Xu, T., Girma, A., \& Yuan, Z., 2017. Regional Correlation between Precipitation and Vegetation in the HuangHuai-Hai River Basin, China. Water, 2017, 9(8), 557. 
ISPRS Annals of the Photogrammetry, Remote Sensing and Spatial Information Sciences, Volume IV-2/W5, 2019

ISPRS Geospatial Week 2019, 10-14 June 2019, Enschede, The Netherlands

Zhang, B., Cao, J., \& Bai, Y., 2012. Effects of rainfall amount and frequency on vegetation growth. Climatic Change, 197-212. 